CASE REPORT

\title{
A patient with a VEGF and endostatin producing gastrointestinal autonomic nerve tumour
}

\author{
A H G Hansma, Y van Hensbergen, B C Kuenen, P J van Diest, R Hanemaaijer, S Meijer, \\ H M Pinedo, K Hoekman
}

J Clin Pathol 2004;57:536-538. doi: 10.1136/jcp.2003.012393

Tumour associated neovascularisation has been characterised as chaotic and insufficient. This report details the results of the analysis of angiogenic factors in tumour cyst fluid, pleural fluid, and blood from a patient with a gastrointestinal autonomic nerve tumour. The tumour produced vascular endothelial growth factor and endostatin in large quantities, which may explain the dysfunctional angiogenesis and tendency to bleeding seen in this tumour type.

T he gastrointestinal autonomic nerve tumour (GANT) was first described in 1984 by Herrera as a subtype of gastrointestinal stromal tumours. ${ }^{1}$ These tumours are thought to arise from the interstitial cells of Cajal. They are composed of spindle shaped cells with eosinophylic fibrillary cytoplasm arranged in a fascicular or palisaded pattern and with ovoid nuclei. In the stroma there is often microcytic degeneration and lymphocytic infiltration. The cells commonly express CD117 (c-kit) and CD34, in addition to neurone specific enolase (NSE) and S-100. ${ }^{2}$ GANTs commonly arise along the gastrointestinal tract and metastasise to the liver and neighbouring structures. A striking vascularity has been mentioned, associated with cysts filled with blood and bleeding as a presenting symptom. This suggests active but dysfunctional neovascularisation. Therefore, proteins involved in angiogenesis are of interest, including vascular endothelial growth factor (VEGF), basic fibroblast growth factor (bFGF), proteases, and endostatin. VEGF and bFGF have been shown to stimulate endothelial proliferation and migration in vitro, and tumour growth and metastasis in vivo. ${ }^{34}$ Matrix metalloproteases (MMPs) and proteases from the plasminogen activator family (PAs) are thought to be essential for the degradation of the extracellular matrix, thereby allowing the invasion and migration of cells. ${ }^{5}$ Endostatin, a $20 \mathrm{kDa} \mathrm{C}$ terminal domain of collagen XVIII, a collagen that is present in basement membranes, ${ }^{6}$ inhibits the growth and migration of endothelial cells in vitro, in addition to the growth of tumours and their metastases in vivo. ${ }^{7}$

In this case report, we explored the angiogenic process, reflected by VEGF, bFGF, endostatin, and various proteases in tumour fluid, pleural fluid, and blood from a patient with a GANT.

\section{CASE REPORT}

In 1993, a 24 year old woman underwent a laparotomy because of bleeding in the liver. A hemi-hepatectomy was performed and revealed a tumour of $11 \times 15 \mathrm{~cm}$; in addition a $3 \mathrm{~cm}$ tumour was resected from the ileum. The tumours were diagnosed as GANT. In 1998, surgery was performed because of multiple GANT lesions in the pelvis. In May 2001, tumour cyst fluid was taken from a liver lesion and pleural fluid during an episode of pleurodesis. In 2002, the patient died because of bleeding in a lung metastasis.

\section{MATERIAL AND METHODS}

Sections ( $4 \mu \mathrm{m}$ thick) were cut from formalin fixed, paraffin wax embedded sections and mounted on Superfrost Plus slides (Menzel, Germany), dried overnight, dewaxed, and dehydrated. Next, antigen retrieval was performed with $10 \mathrm{mM}$ citrate buffer $(\mathrm{pH} 6.0)$ at $100^{\circ} \mathrm{C}$ in a microwave oven, pretreatment was performed with either trypsin or pepsin in the Nexes IHC automated immunostainer (Ventana, Strassburg, France). Endogenous peroxidase activity was blocked with $0.03 \%$ hydrogen peroxide in methanol for 10 minutes. Slides were stained either by hand or in the automated immunostainer according to the manufacturer's instructions (Ventana). Slides were washed with phosphate buffered saline between steps. Visualisation was performed with either diaminobenzidine or envision kit; subsequently, the slides were counterstained with haematoxylin, dehydrated, and mounted in DePeX mounting medium (BDH Laboratory Supplies, Poole, Dorset, UK). CD34, mouse monoclonal (ms-mono), CDl17 (ms-mono), chromogranin (ms-mono), anti-NSE (ms-mono), anti-S-100 (rabbit polyclonal), K6, and K20 (ms-mono) were purchased from Dako (Ely, Cambridgeshire, UK). The antibody to vimentin (msmono) was a gift from Dr J Hilgers (Department of Gynaecology, VUMC, Amsterdam, the Netherlands).

For electron microscopy, fragments of the tumour were fixed in $2 \%$ glutaraldehyde, postfixed in osmium tetraoxide, dehydrated with ethanol, and embedded in Epon. Ultrathin sections were collected on Formavar coated copper grids. The sections were contrasted with uranyl acetate and lead citrate and examined in a JEOL 1200 EX electron microscope.

The VEGF and bFGF enzyme linked immunosorbent assay (ELISA) kits were from R\&D Systems (Minneapolis, Minnesota, USA) and the endostatin ELISA was from Cytimmune (College Park, Maryland, USA).

The MMP-2 and MMP-9 activity assays were from Amersham Biosciences (Cardiff, UK). These assays separately measure active and total (active plus latent) activity. Protein concentrations of MMP-2 and MMP-9 were measured with a standard quantitative ELISA, as described previously. ${ }^{8}$ The urokinase PA (uPA) protein concentration was measured by means of the immunoassay kit: u-PA EIA HS (Taurus, Leiden, the Netherlands). The activity of UPA and plasmin was determined as described previously. ${ }^{9}$ The tissue PA (tPA)

\footnotetext{
Abbreviations: bFGF, basic fibroblast growth factor; ELISA, enzyme linked immunosorbent assay; GANT, gastrointestinal autonomic nerve tumour; MMP, matrix metalloprotease; ms-mono, mouse monoclonal antibody; NSE, neurone specific enolase; PS, plasminogen activator; STS, soft tissue sarcomas; PPA, tissue plasminogen activator; UPA, urokinase plasminogen activator; VEGF, vascular endothelial growth factor
} 
antigen was determined using a specific tPA ELISA (Biopool Int, Umea, Sweden).

\section{RESULTS}

Histopathology revealed a mesenchymal proliferation, negative for keratins, and with focal positivity for c-kit and CD34. Vimentin, S-100, NSE, and chromogranin were positive. Eleven mitoses $/ 2 \mathrm{~mm}^{2}$ were found. The vascularisation of the tumour tissue was exuberant. VEGF was expressed abundantly in this tumour and large cysts with VEGF positivity were present (fig 1).

Electron microscopic examination revealed the focal accumulation of desmosomes in the tumour cells. Dense core granules were seen in the cytoplasm of the tumour cells and microtubules were present focally. Intercellular skeinoid fibres were absent but collagen fibres, approximately $20 \mathrm{~nm}$ thick, were seen.

Tables 1 and 2 show data from the patient's tumour fluid, pleural fluid, and blood. There were high concentrations of both VEGF and endostatin in all three sample types. The production and activity of MMP-2, MMP-9, and UPA was reduced in tumour fluid. The concentration of tPA and the activity of plasmin were higher than those seen in tumour fluid from nine other patients with sarcoma.

\section{DISCUSSION}

GANTs are associated with bleeding, haemorrhagic cysts, and a high vascularity, ${ }^{12}$ as was the case in our patient. Large intratumoral cysts have been described as a frequent characteristic of soft tissue sarcomas (STS) in general, and these cysts often contain high amounts of VEGF, ${ }^{10}$ which is a permeability factor also. The concentration of VEGF, but not of bFGF, was extremely high in tumour fluid, pleural fluid, and in serum from our patient.

A remarkable finding was the increased concentration of endostatin in tumour fluid, pleural fluid, and plasma of our patient. This is an unusual finding because the concentration of endostatin in the tumour fluid from nine other STS was not different from the normal plasma value, and the concentrations of endostatin in pleural fluid and ascites were also not increased in a series of 92 samples from a broad spectrum of cancer types. ${ }^{11}$ This finding suggests that this GANT tumour generated (an) enzyme(s) capable of degrading CXVIII to endostatin. Increased serum concentrations of

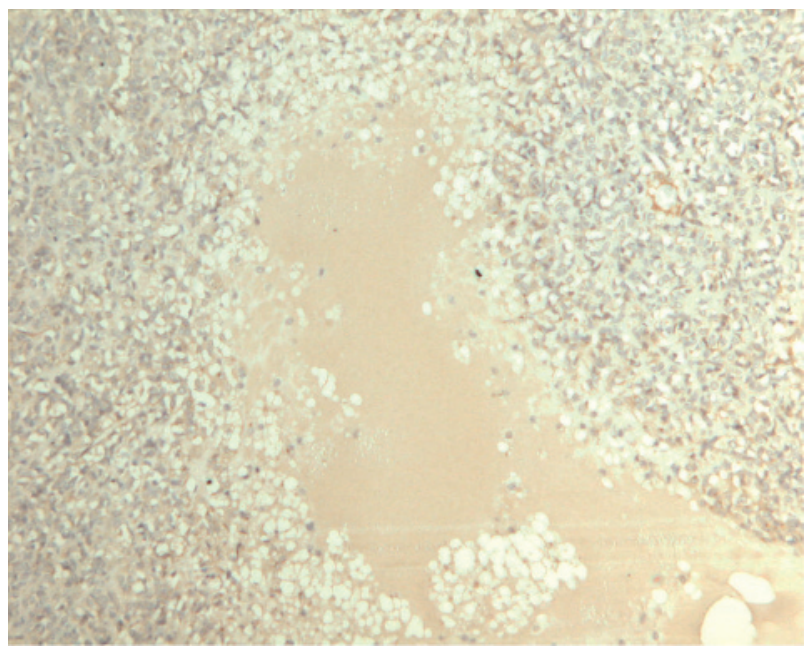

Figure 1 Immunohistochemical staining for vascular endothelial growth factor showing pseudocyst formation with positively (brown) stained cyst fluid, and positive tumour cells surrounding the cyst (original magnification, $\times 10$ ).
Table 1 Angiogenic proteins in tumour fluid

\begin{tabular}{|c|c|c|c|}
\hline & \multirow[b]{2}{*}{ Patient } & \multicolumn{2}{|c|}{9 other STS patients } \\
\hline & & Median & Range \\
\hline VEGF $(\mathrm{pg} / \mathrm{ml})$ & 7026 & 15529 & $698-51425$ \\
\hline bFGF (pg/ml) & 5.4 & & $0.8-941$ \\
\hline Endostatin (ng/ml) & 371 & 26 & $10-65$ \\
\hline \multicolumn{4}{|l|}{ MMP-2 } \\
\hline Active $(\mathrm{U} / \mathrm{ml})$ & 0 & 0 & 0 \\
\hline Total (U/ml) & 705 & 1190 & $820-9440$ \\
\hline Protein $(\mathrm{ng} / \mathrm{ml}$ ) & 907 & 1550 & $818-4433$ \\
\hline \multicolumn{4}{|l|}{ MMP-9 } \\
\hline Active $(\mathrm{U} / \mathrm{ml})$ & 60 & 115 & $0-1715$ \\
\hline Total (U/ml) & 520 & 1840 & $410-17090$ \\
\hline Protein $(\mathrm{ng} / \mathrm{ml}$ ) & 78 & 160 & $113-160$ \\
\hline \multicolumn{4}{|l|}{ UPA } \\
\hline Active $(\mathrm{U} / \mathrm{ml})$ & 5270 & 10835 & 8010-19930 \\
\hline Total (U/ml) & 5525 & 13235 & $9010-22975$ \\
\hline Protein $(\mathrm{ng} / \mathrm{ml})$ & 7 & 42 & $4-124$ \\
\hline tPA (ng/ml) & 370 & 18 & $3-1418$ \\
\hline Plasmin $(\mathrm{U} / \mathrm{ml})$ & 25880 & 4600 & $0-16120$ \\
\hline
\end{tabular}

Normal values: VEGF in plasma, $<55 \mathrm{pg} / \mathrm{ml}$, in serum $200-300 \mathrm{pg} / \mathrm{ml}$; bFGF in plasma/serum, $<6.9 \mathrm{pg} / \mathrm{ml}$; endostatin in plasma $/$ serum, 20$25 \mathrm{ng} / \mathrm{ml}$.

bFGF, basic fibroblast growth factor; MMP, matrix metalloprotease; STS, soft tissue sarcomas; IPA, tissue plasminogen activator; UPA, urokinase plasminogen activator; VEGF, vascular endothelial growth factor.

endostatin in patients with STS, associated with an increased risk of tumour recurrence after resection, have been reported previously. ${ }^{12}$ The role of endostatin in the biology of these tumours warrants further study.

\section{"A remarkable finding was the increased concentration of endostatin in tumour fluid, pleural fluid, and plasma of our patient"}

Mechanistic studies have not yet firmly established a unique receptor or target for endostatin. Binding to cell surface integrins $\left(\alpha_{5} \beta_{1}\right)$, blocking the VEGF-KDR/Flk-1 interaction, and binding the catalytic domain of MMP-2 have been suggested. ${ }^{13-15}$ In the tumour fluid of our patient, the activity of MMP and UPA was reduced, but the tPA protein concentration and plasmin activity were greatly increased, which is in accordance with the mechanism of action suggested by Reijerkerk et al. ${ }^{16}$ These workers suggested that VEGF induces hyperpermeability of vessels, resulting in the local influx of plasma proteins and the generation of a fibrin containing "provisional matrix", which facilitates the migration of endothelial cells. However, excessive degradation of this matrix by increased plasmin activity may have largely contributed to a high turnover of blood vessels and the bleeding tendency in this tumour.

In the case reported here, increased production of VEGF was accompanied by the generation of endostatin. Because VEGF initiates angiogenesis, resulting in the generation of immature vessels, and endostatin inhibits angiogenesis,

Table 2 Angiogenic proteins in plasma, serum, and pleural fluid (PF)

\begin{tabular}{llll}
\hline & PF & Plasma & Serum \\
\hline VEGF $(\mathrm{pg} / \mathrm{ml})$ & 2239 & 80 & 1540 \\
bFGF $(\mathrm{pg} / \mathrm{ml})$ & 1.5 & 1.9 & 3.0 \\
Endostatin $(\mathrm{ng} / \mathrm{ml})$ & 106 & 45 & 40
\end{tabular}

Normal values: VEGF in plasma, $<55 \mathrm{pg} / \mathrm{ml}$, in serum $200-300 \mathrm{pg} / \mathrm{ml}$ bFGF in plasma/serum, $<6.9 \mathrm{pg} / \mathrm{ml}$; endostatin in plasma/serum, 20 $25 \mathrm{ng} / \mathrm{ml}$.

bFGF, basic fibroblast growth factor; VEGF, vascular endothelial growth factor. 


\section{Take home messages}

- We analysed angiogenic factors in the tumour cyst fluid, pleural fluid, and blood of a patient with a gastrointestinal autonomic nerve tumour and found that large quantities of both vascular endothelial growth factor (VEGF) and endostatin were present

- This is the first description of a tumour producing both the angiogenesis stimulator VEGF and the angiogenesis inhibitor endostatin

- This may explain the dysfunctional angiogenesis and tendency to bleeding seen in this tumour type

ultimately resulting in apoptosis of immature vessels, this combination might have had a negative effect on the integrity of the endothelial lining. Tumour associated neovascularisation has been described as an active, but abnormal and inefficient process, because of the absence of a balanced angiogenesis programme. In this GANT the presence of both VEGF and endostatin could have led to dysfunctional angiogenesis. It remains to be determined whether other GANTs have this angiogenic profile and whether this can explain the relatively mild progression of this disease and bleeding as a complication.

This is the first description of a tumour producing both the angiogenesis stimulator VEGF and the angiogenesis inhibitor endostatin. The investigation of tumour fluid, which can be seen as the in vivo "conditioned medium" of a tumour, was of great help in understanding the dysfunctional vascularisation of this tumour.

\section{ACKNOWLEDGEMENTS}

We thank P van der Groep and G Meijer for their help with immunohistochemistry and $\mathrm{N}$ van Lent for the protease ELISAs and activity assays.

\section{Authors' affiliations}

A H G Hansma, Y van Hensbergen, B C Kuenen, H M Pinedo, K Hoekman, Department of Medical Oncology, Vrije Universiteit Medical Centre, De Boelelaan 1117, 1007 MB Amsterdam, The Netherlands
P J van Diest, Department of Pathology, Vrije Universiteit Medical Centre S Meijer, Department of Surgery, Vrije Universiteit Medical Centre R Hanemaaijer, Gaubius Laboratory, TNO-PG, Leiden, The Netherlands

Correspondence to: Dr K Hoekman, Department of Medical Oncology, Vrije Universiteit Medical Centre, De Boelelaan 1117, 1007 MB Amsterdam, The Netherlands; k.hoekman@vumc.nl

Accepted for publication 21 October 2003

\section{REFERENCES}

1 Herrera GA, Cerezo L, Jones JE, et al. Gastrointestinal autonomic nerve tumors. "Plexosarcomas". Arch Pathol Lab Med 1989;1 13:846-53.

2 Lee JR, Joshi V, Griffin JW, et al. Gastrointestinal autonomic nerve tumor. Immunohistochemical and molecular identity with gastrointestinal stromal tumor. Am J Surg Pathol 2001;25:979-87.

3 Ferrara N. Vascular endothelial growth factor: molecular and biological aspects. Curr Top Microbiol Immunol 1998;237:1-30.

4 Compagni A, Wilgenbus P, Impagnatiello MA, et al. Fibroblast growth factors are required for efficient tumor angiogenesis. Cancer Res 2000;60:7163-9.

5 Pepper MS. Role of the matrix metalloprotease and plasminogen activatorplasmin systems in angiogenesis. Arterioscler Thromb Vasc Biol 2001;21:1104-17.

6 O'Reilly MS, Boehm T, Shing Y, et al. Endostatin: an endogenous inhibitor of angiogenesis and tumor growth. Cell 1997;88:277-85.

7 Boehm T, Folkman J, Browder T, et al. Antiangiogenic therapy of experimental cancer does not induce acquired drug resistance. Nature 1997;390:404-7.

8 Gveric D, Hanemaaijer R, Necombe J, et al. Plasminogen activators in multiple sclerosis lesions: implications for the inflammatory response and axonal damage. Brain 2001; 124:1978-88.

9 Hanemaaijer R, Visser H, Konttinen YT, et al. A novel and simple immunocapture assay for determination of gelatinase-B (MMP-9) activities in biological fluids: saliva from patients with Sjogren's syndrome contain increased latent and active gelatinase-B levels. Matrix Biol 1998;17:657-65.

10 Verheul HMW, Hoekman K, Lupu F, et al. High VEGF concentration, and activation of coagulation pathway, including platelets, in aspirated fluids of soft tissue sarcomas. Clin Cancer Res 2000;6:166-71.

11 van Hensbergen Y, Broxterman HJ, Hanemaaijer R, et al. Soluble aminopeptidase N/CD13 in malignant and non-malignant effusions and intra-tumoral fluid. Clin Cancer Res 2002;8:3747-54.

12 Feldman AL, Pak H, Yang JC, et al. Serum endostatin levels are elevated in patients with soft tissue sarcoma. Cancer 2001;91:1525-9.

13 Rehn M, Veikkola T, Kukk-Valdre E, et al. Interaction of endostatin with integrins implicated in angiogenesis. Proc Natl Acad Sci U S A 2001;98:1024-9.

14 Kim YM, Hwang S, Kim YM, et al. Endostatin blocks vascular endothelial growth factor-mediated signaling via direct interaction with KDR/Flk-1. J Biol Chem 2002;277:27872-9.

15 Lee SJ, Kim YM, Lee HI, et al. Endostatin binds to the catalytic domain of matrix metalloproteinase-2. FEBS Lett 2002;519:147-52.

16 Reijerkerk A, Mosnier LO, Kranenburg O, et al. Amyloid endostatin induces endothelial cell detachment by stimulation of the plasminogen activation system. Mol Cancer Res 2003;1:561-8. 